\title{
Re-Evaluating Megaproject Cost Overruns: Putting Changes Into Perspective
}

\author{
${ }^{1}$ Alan Walsh, 2 Peter Walker \\ 1,2 Maxwell Building, University of Salford, Crescent, United Kingdom
}

\begin{abstract}
The vast sums of money involved in megaprojects, and the perceived lack of public benefit, create controversy. Flyvberg' s iron law asserts that megaprojects are over budget, over time, under benefits, over and over again (Flyvberg, 2018). More recent research suggests that this focus on cost overruns is based on highly misleading data (Love \& AhiagaDagbui, 2017). This research seeks to examine live megaprojects and examine Flyvbjergs theories in practice, through an investigation of current megaprojects in the Middle East. The research provides three case studies for two recently completed and one on-going megaproject, to examine these claims further. The research questions whether the right comparisons are made between the initial offerings and final product, through consultation with professionals. Based on the findings, it is suggested that an increase of over $100 \%$ of the Contract price, may not constitute an over-budget megaproject. Professional Cost Consultants in the built environment can provide greater insight into the complexity that adds cost in the transitions from initial to final costs for megaprojects, although the validity of this insight may be reduced by a lack of distance from or overview of the megaproject. This paper investigates some of the familiar sources of megaproject cost overrun and considers the findings of Cost Consultants engaged in monitoring megaprojects in the state of Qatar. Time and Cost considerations are just two of the characteristics evident in megaprojects. This research suggests that reporting of time and cost overruns is frequently based on limited, misunderstood or misreported data, and that in order to provide higher fidelity, such 'headline claims' need to be careful considered in the context of the original project scope. This paper recognises that cost is just one element of a megaproject, and that megaprojects warrant more holistic considerations including acknowledgement of other significant characteristics such as their embodiment of large components of risk, political influences, organisational pressures and management complexities.
\end{abstract}

Keywords: Cost overruns, Megaprojects, Megaproject characteristics

\section{Introduction}

Headlines in the popular and trade press regularly draw attention to supposed extreme and regular time and cost overruns associated with megaprojects. Examples include the U.K. HS2 high-speed railway (Transcity Rail, 2019), Mexico's recently suspended new airport (Reuters, 2018), Ethiopia's delayed new dam (Ref). Megaprojects such as Dubai's International Airport, Hong Kong Airport or the Panama Canal contribute directly to a significant portion of the country's GDP (Flyvberg, 2017; McKinsey, 2015; Merrow, 1988) and so are essential to the local and global economy. This paper suggests that to arrive at a more accurate assessment of the issues in megaprojects, there is a need to consider all the project complexities and recommends a departure from the prioritisation of cost and time issues. While much of the research to date is dominated by EU related megaprojects (Flyvbjerg, Holm, \& Buhl, 2002), this paper captures current Middle Eastern data. Large scale megaprojects are prominent in the Middle East, with the inclusion of projects such as the $\$ 500$ billion NEOM megaproject in Saudi Arabia or the new $\$ 50$ billion Lusail City in Qatar (GCR, 2018; Lusail, 2019). Current research considers cost overrun as the increase from the initial costs of a megaproject to its final costs (Flyvbjerg et al., 


\author{
Alan Walsh, Peter Walker \\ Re-Evaluating Megaproject Cost Overruns: Putting Changes Into Perspective
}

2002). The author suggests that this logic is fundamentally flawed, as the initial product and final product are often quite different. This research examined three case studies involving "over-budget" megaprojects in the GCC. It provided a \% comparison between the contract sum and the additional outturn costs, noting that the megaproject final costs reflected increases of between $17 \%$ to $113 \%$ of the contract sum. The paper investigates the factors which influenced these budget increases, to put these changes into perspective.

\title{
2. Defining Megaprojects and Examining Their Reputation
}

Megaprojects are typically described as large-scale, complex ventures costing a billion dollars or more, take many years to develop and build, involve multiple public and private stakeholders, are transformational, and impact millions of people (Davies, Dodgson, Gann, \& Macaulay, 2017; Flyvberg, 2017; Mok, Shen, \& Yang, 2015; Pollack, Biesenthal, Sankaran, \& Clegg, 2018a; Turner, 2018). Megaprojects have been described as wild beasts ......., hard to tame, known for their complexity, vast size, expensive cost, and long-time frame (Zidane, Johansen and Ekambaram, 2013). They were once considered privileged particles of the development process Hirschman (1995: vii, xi), but recent research indicates that they are growing ever larger and their scale seems to be accelerating (Flyvberg, 2017). Megaprojects are inevitably accompanied by a perception of a lack of benefit to attract public scrutiny. Criticisms have recently been levied against the U.K.'s HS2 high-speed railways (Transcity Rail, 2019), Mexico's recently suspended new airport (Reuters, 2018) or Ethiopia's delayed new dam (GCR, 2018). It has also been identified that the high financial cost of megaprojects such as Dubai's International Airport, Hong Kong Airport or the Panama Canal contributes directly to a significant portion of the country's GDP (Flyvberg, 2017; McKinsey, 2015; Merrow, 1988). The vast sums of money involved in these ventures and the perceived lack of benefits to the public such as Mexico's airport or Ethiopia's Dam create controversy. There are also cases where megaprojects may be seen as financial failures, yet perceived by the public as a success, such as the UK- France Channel Tunnel or the Sydney Opera house (Flyvbjerg, 2018).

\subsection{Megaprojects as a Number}

The traditional linking of a megaproject as a project higher than one billion is linked to Capka (2004). He has been credited with establishing a megaproject benchmark value of one billion dollars for the new different breed of the project (megaproject) which was emerging in infrastructure projects for the United States Department of Transportation. Many countries have since followed suit, associating a monetary value of one billion units. These include Hong Kong one billion dollars (Mok et al., 2015); the UK one billion pounds (Flyvberg, 2017) and Europe considers projects of one billion euros (Pau, Langeland, \& Njå, 2016). As costs are subject to inflationary pressures and continue to expand, researchers now consider augmented titles, such as the existence of Giga projects and Tera projects (Flyvbjerg et. Al., 2014). Researchers also refer to a new variety of enhanced or complex megaprojects Hillson (2018). It is evident that one billion of a local currency may have a significant impact on that countries GDP (Gross Domestic Product, yet the scale of some recent GCC projects, such as Saudi Arabia's $\$ 500$ billion Neom city (GSR news, 2017) or Qatar's \$46 billion Lusail City project (www.lusail.com) make one billion pounds appear an inappropriate measure. While critics may refer to budget overruns and time overruns (Flyvberg, 2017, 2018; Flyvbjerg, 2014b), it is worth noting that a megaproject's scope often grows and expands throughout its lifespan. It is misleading to relate initial costs to final costs when significant changes may be occurring during the megaproject's evolution. This paper suggests that when one compares the starting and final product, then labelling this increase as overbudget costs may not be accurate as we are comparing different scopes of works, the proverbial apples versus oranges scenario. A case study of three GCC megaprojects is used to examine the impact of changes on megaproject budgets. 


\section{The Search for a More Holistic Definition of Megaprojects}

Despite the often unique and temporary nature of megaprojects, research has shown that they often exhibit core characteristics. These may include short-term temporary collaborations for bespoke developments (Van Marrewijk, Veenswijk, \& Clegg, 2014). Core megaproject characteristics need to be isolated to permit a more thorough examination of their nuances and interdependencies. After thematic analysis, repeated themes such as their complexity, size, and scale become evident. The Oxford Handbook of Megaproject Management (Flyvbjerg, 2017b) collated views of 43 active megaproject researchers, seeking to understand the complexities of such ventures. The identification of common characteristics is difficult due to the unique nature of many of these projects and the knowledge that they are often considered as temporary endeavours (Brookes, Sage, Dainty, Locatelli, \& Whyte, 2017). They also exhibit temporal characteristics such as task complexity, singularity and innovativeness (Sydow, 2017). Recent research (van Marrewijk, Ybema, Smits, Clegg, \& Pitsis, 2016) emphasises the culture of temporariness within megaprojects makes collaboration critical, difficult and laborious, frequently resulting in underperformance or failure of the megaproject. This analysis also enables a review of how factors such as organisational, national or professional culture may influence megaproject governance. Such analysis helps outline the high levels of risks associated with megaprojects. The phenomenon of managing megaprojects is the subject of a European study seeking to understand how megaprojects can be designed and delivered more effectively to ensure their effective commissioning within the European Union (Barbero \& Redi, 2015). Further analysis of megaprojects identifies other factors such as cultural influences impacting their governance, their association with vast levels of risk and their reputation of being notoriously hard to manage, permitting a fuller understanding. Works by (Eweje, Turner and Müller 2012); (Mišić and Radujković,2015) researched and exposed many of the complex characteristics associated with megaprojects. Researchers, including (Pollack 2018; Garemo, Matzinger and Palter 2015; and Flyvberg 2017), have highlighted critical characteristics which caused completed megaprojects to succeed or fail.

A thematic analysis of these characteristics includes:

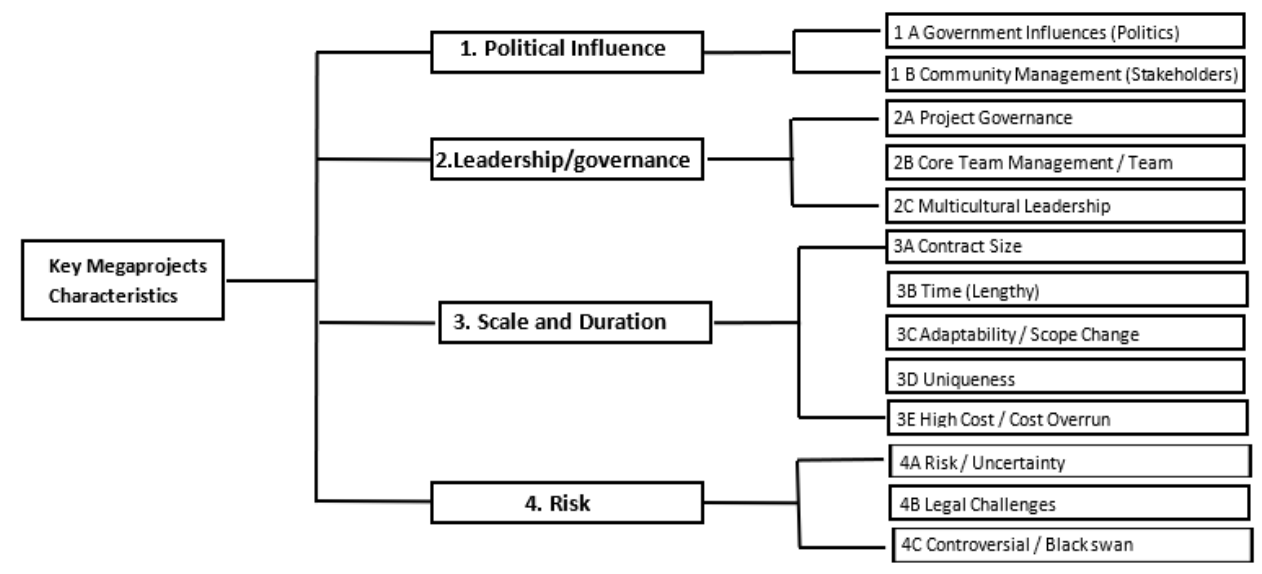

Figure 1. - Thematic analysis

\subsection{Time \& Cost Considerations}

Based on the isolation of a megaproject's characteristics, it is evident that Time and Cost considerations are critical elements in the evaluation of megaprojects. A recent analysis of risks 


\section{Alan Walsh, Peter Walker \\ Re-Evaluating Megaproject Cost Overruns: Putting Changes Into Perspective}

in megaprojects considered published findings, specifically related to risk management in megaprojects. This research found that time and costs risks were the most frequent megaproject risk, as evidenced by their dominance in over forty per cent of published literature reviewed (Irimia-Diéguez, Sanchez-Cazorla, \& Alfalla-Luque, 2014). Flyberg remains a staunch critic of megaproject time and cost overruns and has suggested a systematic falsification of initial costs. He suggests that this represents a Hiding Hand principle (Flyvbjerg, 2014a). This principle suggests that these cost estimates are systematically, and significantly deceptive, and indicated that such distortions are directly related to politics, economic self-interest and the buildings of a monument as a legacy (Flyvbjerg et al., 2002).

In Europe, the majority of megaprojects are either State-funded or shareholder funded. Both funders provide a degree of transparency for financial costs associated with the megaproject outturn costs. Not all data is available as there are significant difficulties in gathering cost data related to megaprojects. The Royal Institute of Chartered Surveyors through its members, provide construction costings on a global basis. They advise the complexities involved in assessing megaproject costs including a decline in the use of Bills of Quantities (the traditional method of pricing projects), proprietary designs and uniqueness and confidentiality as critical sources why accurate cost comparisons cannot be made on a global basis (Horner \& Muse, 2018). Provision of reliable financial data is crucial to the analysis of budget costs, as it allows researchers to establish valid comparisons between the original and final expenses of megaprojects. To date, there is a lack of published cost data for megaprojects associated with the GCC. Due to such lack of data, existing research has concentrated principally on large European projects, (Flyvbjerg et al., 2002). Some general studies are available (Johnson \& Babu, 2018a; Mahdi \& Soliman, 2018), which qualitatively engaged with GCC practitioners and examined the reasons for cost and time overruns in GCC megaprojects. However, they appear to lack of credible substantiation. Despite challenges associated with obtaining megaproject financial data in the GCC, three case studies were undertaken with international Cost Consultants. They provided financial data for some critical GCC megaprojects. The Cost Consultants have disguised confidentially confidential data but retained the ratio of the percentage cost adjustments for the components which impacted the contract sum. Despite this concealment of commercially sensitive data, the causes and proportions of changes represent the actual changes during the lifespan of the megaproject and serve as a benchmark for cost increments (overbudget in Flyvberg's view) of the megaproject.

\subsection{Middle East Megaprojects}

Prior to considering this case study, it is beneficial to review the contextual background of GCC megaprojects, to appreciate how typical GCC megaprojects may differ from those European megaprojects examined by other researchers, such as (Flyvbjerg et al., 2003; Pollack et al., 2018b; van Marrewijk, Smits, Clegg, Pitsis, \& Veenswijk, 2008). The Middle East and in particular the Gulf Cooperative Council (GCC) states extensively use megaprojects to deliver new cities, infrastructure and oil and gas-related projects. (Deloitte 2016) estimated that the GCC has a US $\$ 2$ trillion pipeline of projects under construction or planned. In June 2018, there were 300 active megaprojects, either being tendered or under construction in the GCC (www.constructionweekonline.com/projects). GCC megaprojects engage large numbers of nonEuropean expatriate workers to support the creation of their megaprojects with Individual GCC States' reliance on expatriates, ranges from thirty-two per cent in Saudi Arabia to eighty per cent in Qatar in 2018. There are further challenges due to the mix of workforce culture, the complexities of design, and unique challenges due to the existence of multiple cultures involved in managing the process (Johnson \& Babu, 2018b). Statistics indicate that the GCC engages almost nine million personnel in its construction sector, nearly twice the 4.8 million staff employed throughout the European Union, (Statista, 2019). In monetary terms, the value of construction-related activities accounts for nineteen per cent of GDP in the GCC which represents twice the estimated nine per cent construction spend in Europe (European Building Confederation 2019). Table 1 summarises critical considerations for GC megaprojects by 


\section{Alan Walsh, Peter Walker \\ Re-Evaluating Megaproject Cost Overruns: Putting Changes Into Perspective}

combining data related to GDP (World bank data, 2019) and population data (data.worldbank.org). It applies Central Intelligence Agency data, which estimates the percentages of expatriate and considers construction AECOM, (2018).

Table 1: GCC Statistics (AECOM, 2018; Central Intelligence Agency, 2019; World bank data, 2019) Expatriate Statistics Qatar www.mdps.gov.qa; Oman www.ncsi.gov.om; Bahrain www.blmi.Imra.bh; UAE www.grc.net; Saudi Arabia; Kuwait www.ceicdata.com/en/kuwait

\begin{tabular}{|l|c|r|r|c|c|c|c|}
\hline & GCC State & $\begin{array}{c}\text { Total } \\
\text { Population }\end{array}$ & $\begin{array}{c}\text { Expatriate } \\
\text { Population }\end{array}$ & $\begin{array}{l}\text { Expatriates } \\
\text { Residents }\end{array}$ & $\begin{array}{l}\text { \% Expats in } \\
\text { Construction }\end{array}$ & $\begin{array}{c}\text { GDP } \\
\text { USD Billion }\end{array}$ & $\begin{array}{c}\text { Value of } \\
\text { Construction } \\
\text { USD, Billion }\end{array}$ \\
\hline 1 & Qatar & $2,639,211$ & $2,111,369$ & $80 \%$ & $50 \%$ & 167.605 & 46.4 \\
\hline 2 & KSA & $32,938,213$ & $10,500,000$ & $32 \%$ & $36 \%$ & 683.827 & 109 \\
\hline 3 & UAE & $9,400,145$ & $7,800,000$ & $83 \%$ & $30 \%$ & 382.575 & 87.7 \\
\hline 4 & Kuwait & $4,136,528$ & $2,895,570$ & $70 \%$ & $17 \%$ & 120.126 & 12.6 \\
\hline 5 & Oman & $4,636,262$ & $2,086,318$ & $45 \%$ & $31 \%$ & 72.643 & 15.2 \\
\hline 6 & Bahrain & $1,492,584$ & 666,000 & $45 \%$ & $22 \%$ & 35.307 & 7.7 \\
\hline 7 & Totals & $55,242,943$ & $26,059,256$ & $47 \%$ & $31 \%$ & $1,462,083$ & 279 \\
\hline
\end{tabular}

As indicated in column six, construction personnel account for between seventeen and fifty per cent of all expatriates within a particular state. Construction-related activities currently account for nineteen per cent of the GCC's Gross Domestic Product (World Bank, 2019). The nine million expatriate construction staff employed on GCC mega-projects, make the workforce for these projects multicultural (Dulaimi \& Hariz, 2011), with the management often comprising an extensive gathering of culturally diverse hired in expert consultants (Archibald et al.,1991) assembled from a pool of highly qualified resources around the world (El-sabek, 2017).

\section{Research Design and Approach}

Case studies are considered a suitable method to examine complex projects within the built environment, such as megaprojects. Case Studies permit the investigator to retain the holistic and meaningful characteristics of real-life events, together with providing an ability to capture rich and complex data (Barrett \& Sutrisna 2009). The author was working in the Middle East state of Qatar at the time of the research and had access to several firms of Cost Consultants in Qatar. There were eight live megaprojects at the time of the study (Summer 2019), and the Cost Consultants involved in these megaprojects were requested to participate in this research. Six western consultants were involved in the eight live megaprojects. Three agreed to join within the stipulated time frame (three months), while others refused citing time constraints, workload or confidentiality reasons for their non-participation. Two of the three cost consultants feature in the top ten cost consultancy practices (Building Magazine, 2019), and the third practice is based in Lebanon, which has multiple offices in the Middle East.

\subsection{Quantitative or Qualitative Approaches}

There is a debate between the quantitative approach taken by Flyvberg in his review of 258 Infrastructure projects sample (Flyvbjerg et al., 2002) and the earlier qualitative research by Hirschman (Lepenies, 2018). Flyvberg suggested that Hirschman overstated his concepts based on a limited number of observations and biased data, while Lepine's contends that Hirschman's data provided half a century ago remains sound in principle (Lepenies, 2018). One of Hirschman's suggestions is that some megaprojects succeeded by creatively responding to their context and succeeded through a form of luck or chance. Flyvberg suggests the this reflects a hiding hand principle as a fallacy of beneficial ignorance (Flyvbjerg, 2016) In his paper he argues that construction Estimators provide unrealistically optimistic outlooks - overestimating benefits and potential success, yet substantially underestimate costs. A review of 161 World Bank-funded 


\section{Alan Walsh, Peter Walker \\ Re-Evaluating Megaproject Cost Overruns: Putting Changes Into Perspective}

projects found evidence of the presence of influences including problem-solving, opportunity costs and luck (Ika, 2018).

Quantitative data may be taken from the figures provided by public accounts or shareholders year-end financial numbers may indeed offer an opening and closing balance for costs associated with a Megaproject. It is the authors view that expert construction knowledge and qualitative interpretation is required to understand why prices have increased and if they are the result of initial deceptive underestimations or the result of changing requirements. This research seeks to capture the experience of directors within such expert western Cost Consultancies. There was also a time constraint associated with a quantitative or qualitative choice in methodology. Flyvbjergs data was assembled over desk research for four years (Flyvbjerg et al., 2002), while the contributors to this research typically have between 15 and 20 years of field exposure and were able to make use of this extensive practical experience. As the subject of interest, requires extensive feedback from the practising participants, semistructured interviews were arranged around core themes and included the opportunity for the respondent to provide unstructured observation and analysis of the subject problem. Interviews were conducted on face to face basis. The initial meeting recorded the original scope and financial details of the project, confirming opening and closing account balances. These are detailed in Appendix 1. A series of follow-up interviews took place (three per case study) during which significant changes, both positive and negative, were analysed. This information provided the delta between the original and final price cost overrun (Flyvberg' s overbudget). This data was analysed and presented in annual increments, spanning the megaprojects lifespan except for one on-going megaproject. Once significant variations were identified, the reasons for these changes were explored. Following the completion of this review and the interpretation of the data, the data was summarised, tabulated and returned to the provider to review its authenticity. To retain confidentiality, the parties adjusted the figures (keeping accurate to the ratio of the variations) and endorsed its use in this case study.

\section{Interrogation of Three GCC Case Studies to Investigate the Impact of Changes}

Experienced construction professional consultants expect changes. In international contracts, provisions are made to anticipate and govern changes to the original scope. An extensively used form of contract - FIDIC - an acronym for the International Federation of Consulting Engineer controls such changes using specific conditions of the agreement, Clauses 8 and 13 (FIDIC, 1999). These changes have time, and cost implications and the Contract Price gets adjusted accordingly in a process labelled as variations. The initially agreed price is known as the contract sum. At the end of the project, a final account is prepared based on the original contract price and the adjustment of all variations issued on the project. This concludes the contract and provides a final sum for the megaproject (Clause 14). The methodology used by researchers, including Flyvberg is to measure the difference between actual and estimated costs (Flyvbjerg et al., 2002). This equates to comparing the original contract sum with the agreed final account. A diverse set of megaprojects was selected for this research including an Airport, a Financial Hub and a new City. GCC megaprojects are generally large projects with a construction duration of up to ten years, such as the examples in the case studies considered within this research. While it may seem appropriate for Airports to engage the most advanced technology available, such as advancements in specialist radar systems, these technological advancements often come at a cost. Similarly, in the case of the new city, may seek to cater for updated infrastructure systems, such as a free-flow traffic movement and smart city requirements. These updates also attract a cost. The city's retail and recreational needs were also updated to incorporate demographics trends. The size of its commercial units, square footage of its tenant and public transport availability influenced variations to the original concept of the City. The Financial District responded to the revised office needs of relocating companies. Current 


\section{Alan Walsh, Peter Walker \\ Re-Evaluating Megaproject Cost Overruns: Putting Changes Into Perspective}

research models fail to consider these natural progressions and may be classified as overbudget. The necessity to make changes and this impact on the financial outcome of three megaprojects are explored in the following Case Studies.

\subsection{Case Study A - Financial District - Project Details}

A new Financial District was developed for West Bay containing 700,000 $\mathrm{m}^{2}$ of built-up area. The development comprises of 9 high-rise office towers, each up to 52 storeys in height, a fivestar hotel, 15 podiums, state-of-the-art elevated car parking for 5,000 cars, primary substations and an energy centre. The Financial District is was designed to serve the global, regional and local financial sector. The project commenced in 2008 and construction was completed in early 2016. This was significantly later than its planned duration of five years, and the budget increased by seventeen per cent. The financial details are provided in Appendix 1.

\section{Changes During the Construction of the Megaproject}

Initially, the project suffered delays as the Employer restructured his organisation. This revision changed the planned occupation and fit-out for one full 52 storey tower. For the first five years of the project, 2008 - 2012, the project budget was reduced. On investigation, the Cost Consultant explained these reductions were the result of both value engineering and the omission of previously planned works. One definition of value engineering describes it as a process wherein the designers are requested to retain the same function at a lower price (Janani, 2019). The changes included a lowering in the thermal rating for glazing to the tower façade and accounted for a $2 \%$ reduction in the overall project costs, which represented a saving of around $£ 120$ million. Other minor cost variations occurred, and a significant budget increase was encountered in 2014 - 2015. As the overall size of the development appeared unchanged, the Cost Consultant was asked to explain the increment. His responded that a new tenant had purchased the development in its entirety. The rapidly declining price of commodities during 2014 and 2015, resulted in the client reducing his spending budget and deferring works to suit his adjusted cash-flow, in addition to reconsidering his office requirements, directing his advisers to alter parking and office space requirements. This resulted in a reduction in open areas, revised sizing of offices, increased car parking provisions and associated mechanical and electrical re-work. These were the significant changes with further details provided in Appendices 1 . Overall the Cost Consultant confirmed that the project might have resulted in saving due to the optimisation of finishes, had the change of use not been applied. The $17 \%$ cost overrun, and the three-year delay period was accepted as attributable to changes in scope. Significantly the Cost Consultants viewed the project as a financial success.

\subsection{Case Study B - Airport Extension - Project Details}

The project involved the extension to an International Airport including departure and arrival lounges, with a built-up area of $134,000 \mathrm{~m} 2$ including the full fit-out of lounges and food and beverage facilities. The construction contract was awarded in two phases. Phase 1included the main body of the Airport, and Phase 2 the nodes or extensions to the main body. This Phase 2 megaproject was awarded in 2009, and the building shell was structurally complete in 2014. The internal fit-outs and lobbies were undertaking a fit-out which was finished by late 2016.

\section{Changes During the Construction of the Megaproject}

The costs associated with this project increased by $113 \%$ of the original contract sum. The Cost Consultants figures were analysed as detailed in Appendix 1. Following analysis of these figures, it became apparent that substantial additional works were incorporated to cater for an addition fit-out for lounges in the airport. These extra works were awarded in 2012 and 2014 for business class lounges, economy lounges, and a large number of restaurants and retail fit-outs. As these 


\author{
Alan Walsh, Peter Walker \\ Re-Evaluating Megaproject Cost Overruns: Putting Changes Into Perspective
}

works did not form part of the original scope of works, they are categorised as variations. By removing these additional works from the contract scope, the suggested overrun reduced further from $113 \%$ to $55 \%$. Further investigations examined a significant budget rise between 2015 and 2016. These investigations revealed that the massive spike in costs was associated with the award of the fit-out for a 5-star transit hotel. This luxurious hotel, incorporating a spa and fit-out accounted for over $25 \%$ of the initial budget increase. Following reduction of the additional lounges fit-out ( $58 \%$ of the overrun) and the hotel fit-out costs ( $25 \%$ of the overrun) the project costs had increased by $17 \%$. Cost Consultants then categorised these figures into different elements. Some $8 \%$ were allocated to Airport security and technological enhancements and the balance $9 \%$ had various uses, e.g. a specific aesthetic enhancement. The Contractors had also submitted claims for additional costs and management fees throughout the additional works. These were dealt with as overheads associated with the fit-out packages and the final accounts closed. Overall the Cost Consultant confirmed that the project was considered financially justifiable and that value for money was achieved. Despite the headline budget increase of $113 \%$ and three-year delays, this project is not viewed as overbudget.

\title{
5.3 Case Study C - New City - Project Details
}

This New City comprises of thirty-five square kilometres of land and water. The total land area is approximately twenty square kilometres. The City provides residential housing for about 195,000 residents, with mixed-use of retail, commercial, hotels, community facilities and recreational areas. It has an anticipated work and residential population of 450,000 . The project commenced in 2012 and is continuing with an expected completion of 2021. This is significantly longer than its planned duration of five years, and the budget has increased by twenty-four per cent to date.

\section{Changes During the Construction of the Megaproject}

This twenty-four per cent cost increase would equate to $£ 1.5$ billion. The city was developed through various masterplans which emerged as the city evolved. There was a total of 17 masterplans reflected a significant progression with changes in land use within the city. Additional infrastructure works were done including other bridges to cater for newly created islands. The mix of retail and residential evolved as investors purchased plots, and the city met updated standards from the Statutory Authorities governing road and utility standards throughout the state. These included changes to the Traffic Control systems, a nationwide initiative to make key roads intersecting the Country as Freeflow (no traffic lights). The road authorities removed roundabouts from current construction projects and generally upgraded the specifications for road surfacing and lighting. The revised mix of tenants also gave rise to a significant change in the utility distribution network and associated facilities (substations and transformer capacities).

Based on a reduced income from commodities from 2014 to 2016, there was a Statewide initiative to reduce the costs of infrastructure projects, including the postponement or cancellation of services considered as non-essential. This resulted in reductions to the number of staff engaged in the management of the construction process and the reduction in rates and salaries to all parties. Deferment of non-essential landscaping, removal of provisions for Artwork and ornate lighting proposals were considered to reduce the budget. The project is still progressing using reduced rates for consultants. The scale and scope of works have increased to cater for timely completion of the works before the 2022 World Cup as the intended venue for the closing ceremony. Overall the Cost Consultant believes that value for money was achieved. The cost budgets have been increased, and despite the forecast, six-year overrun, the revised and improve city shall be seen as a financial success.

\subsection{Overall Findings}




\section{Alan Walsh, Peter Walker \\ Re-Evaluating Megaproject Cost Overruns: Putting Changes Into Perspective}

Individually each of the three megaprojects experienced multiple changes through their evaluation. At first view, these megaprojects were over budget by $17 \%, 113 \%$ and $24 \%$ equating to a cost increase of almost two billion pounds. They were each impacted by a global downturn in oil prices and incurred substantial variations and time delays throughout their lifespan. Despite each megaproject being over budget, each of the Cost Consultants considered the project as a financial success. This is based on their experiences with construction costs and the knowledge that variations cost money. They do not find that the megaproject was overbudget, as they have appropriately adjusted the initial budget progressively to match the Employers updated requirements.

\section{Conclusions and Way Forward}

This research recommends that cost overruns in megaprojects should be evaluated by capturing the detailed contextual knowledge of the project construction cost consultant and avoid the simplistic approach of deducting the initial and final costs and labelling all differences as 'overbudget'. While time and cost risk make up a reported 40 plus per cent of documented risk and is prey to sensational headlines, this author recommends that megaprojects should be considered at a more holistic level. When gauging the success or failure of megaprojects, it is essential to examine all complexities and characteristics associated with megaprojects, such as the consideration of risk and culture (Garemo et al., 2015; Pollack et al., 2018a; Söderlund et al., 2017). It is well known to professional construction consultants that the cost increases in such megaprojects are often explained by changes to the project scope. It urges caution in the use of distorted figures and allegations of financial mismanagement, without a fuller examination of the facts. Three megaproject case studies in the Middle East were carried out, and all found evidence from the cost consultants that increases of up to two billion pounds were explained and justified and the project cannot, therefore, be accurately described as 'over budget'.

\section{References}

- AECOM. (2018). Middle East Property \& Construction handbook.

- Archibald, R. D. (1991). Overcoming cultural barriers in project management. Project Management Journal, 5(4). from http://marketplace.pmi.org/Pages/ProductDetail.aspx?GMProduct $=00100568800$ \&iss $=1$

- Barbero, M. C., \& Redi, H. (2015). The importance of what is at stake in megaprojects. Retrieved June 1, 2019, from https://www.pmi.org/learning/library/importance-stakemegaprojects-9647

- Barrett, P., \& Sutrisna, M. (2009). Methodological strategies to gain insights into informality and emergence in construction project case studies. Construction Management and Economics, 27(10) Crossref

- Brookes, N., Sage, D., Dainty, A., Locatelli, G., \& Whyte, J. (2017). An island of constancy in a sea of change: Rethinking project temporalities with long-term megaprojects. International Journal of Project Management, 35(7). Crossref

- Building Magazine. (2019). Top 50 QSs 2017 | Features | Building. Retrieved July 17, 2019, from https://www.building.co.uk/data/top-50-qss-2017/5089763.article

- Capka, J. R. (2004). Megaprojects -They Are A Different Breed. Federal Highway Administration.

- Central Intelligence Agency. (2019). References:: Guide to Country Profiles - The World Factbook - Central Intelligence Agency. Retrieved January 31, 2019, from https://www.cia.gov/library/publications/the-world-factbook/docs/profileguide.html

- Confederation, E. B. (2019). European Builders Confederation. Retrieved April 30, 2019, from http://www.ebc-construction.eu/index.php?id=3

- Davies, A., Dodgson, M., Gann, D. M., \& Macaulay, S.C. (2017) Five Rules for Managing Large, Complex Projects

- Deloitte. (2016). GCC Powers of Construction 2016 - The funding equation.

- Dulaimi, M., \& Hariz, A. (2011). The impact of cultural diversity on the effectiveness of construction project teams. Engineering Project Organization Journal, 1(4). Crossref 


\section{Alan Walsh, Peter Walker \\ Re-Evaluating Megaproject Cost Overruns: Putting Changes Into Perspective}

- El-sabek, L. M. (2017). Framework for managing integration challenges of production planning and control in international construction megaprojects.

- Eweje, J., Turner, R., \& Müller, R. (2012). Maximising strategic value from megaprojects: The influence of information-feed on decision-making by the project manager. International Journal of Project Management, 30(6). Crossref

- FIDIC. (1999). International Federation of Consulting Engineers I The Global Voice of Consulting Engineers. Retrieved August 1, 2019, from http://fidic.org/

- Flyvberg, B. (2017). The Oxford Handbook of Megaproject Management. Crossref

- Flyvberg, B. (2018). PMI REVIEW Are project forecasters "fools or liars"?

- Flyvbjerg, B. (2014a). What you should know about megaprojects and why: An overview. Project Management Journal, 45(2). Crossref

- Flyvbjerg, B. (2014b). What you should know about megaprojects and why: An overview. Project Management Journal. Crossref

- Flyvbjerg, B. (2016). The Fallacy of Beneficial Ignorance: A Test of Hirschman's Hiding Hand. World Development. Crossref

- Flyvbjerg, B. (2017). The Oxford Handbook of Megaproject Management. (B. Flyvbjerg, Ed.) (Vol. 1). Oxford University Press. Crossref

- Flyvbjerg, B. (2018). Oral Evidence: The Government's Management of Major Projects (November). Crossref

- Flyvbjerg, B., Bruzelius, N., \& Rothengatter, W. (2003). Megaprojects and Risk an Anatomy of Ambition Crossref

- Flyvbjerg, B., Holm, M. S., \& Buhl, S. (2002). Underestimating costs in public works projects: Error or lie? Journal of the American Planning Association, 68(3). Crossref

- Garemo, N., Matzinger, S., \& Palter, R. (2015). Megaprojects: The good, the bad, and the better. McKinsey \& Company, (July), 8.

- GCR, N. (2018). Ethiopia's huge Nile dam delayed to 2022 - News - GCR. Retrieved April 7, 2019, from http://www.globalconstructionreview.com/news/ethiopias-huge-nile-damdelayed-2022/

- GSR news. (2017). Saudi Arabia to build \$500bn "new global capital" in the desert. Global Construction Review - CIOB, (25/10/2017).

- Hillson, D. (2018). Managing risk in complex megaprojects (webinar) - YouTube. Retrieved February 2, 2019, from https://www.youtube.com/watch?v=PZiuARCsSTM

- Horner, M., \& Muse, A. (2018). Sharing construction cost data - benefits, challenges and opportunities. RICS.Org/Insight (March).

- Ika, L. A. (2018). Beneficial or Detrimental Ignorance: The Straw Man Fallacy of Flyvbjerg's Test of Hirschman's Hiding Hand. World Development, 103. Crossref

- Interventions. Building Research and Information. https://doi.org/10.1080/09613218.2014.86761

- Janani, K. (2019). VALUE ENGINEERING FOR REDUCTION IN COST AND PRODUCTIVITY IMPROVEMENT FOR A CONSTRUCTION, 07(03).

- Johnson, R. M., \& Babu, R. I. I. (2018a). Time and cost overruns in the UAE construction industry: a critical analysis. International Journal of Construction Management, $0(0)$.

- Johnson, R. M., \& Babu, R. I. I. (2018b). Time and cost overruns in the UAE construction industry: a critical analysis. International Journal of Construction Management, $0(0)$.

- Lepenies, P. H. (2018). Statistical Tests as a Hindrance to Understanding: What the Controversy around the "Hiding Hand" Reveals about Research in the Social Sciences and Conceals about Project Management. World Development, 103. Crossref

- Li, H., \& Guo, H. L. (2011). "Complexities in managing mega construction projects." International Journal of Project Management, 29(7). Crossref

- Love, P. E. D. D., \& Ahiaga-Dagbui, D. D. (2018). Debunking fake news in a post-truth era: the plausible untruths of cost underestimation in transport infrastructure projects. Transportation Research Part A: Policy and Practice (April). Crossref

- Love, P. E. D., \& Ahiaga-Dagbui, D. D. (2017). Debunking fake news in a post-truth era: the plausible untruths of cost underestimation in transport infrastructure projects, (April). Crossref

- Lusail. (2019). Lusail City Development Movie. Retrieved April 5, 2019, from https://www.youtube.com/watch?v=0It6MoUMUGc

- Mahdi, I., \& Soliman, E. (2018). Significant and top-ranked delay factors in Arabic Gulf countries. International Journal of Construction Management. Crossref

- McKinsey. (2015). Megaprojects The good the bad and the better.

- Merrow, E. W. (1988). Understanding the Outcomes of Mega-Projects. RAND. 


\section{Alan Walsh, Peter Walker \\ Re-Evaluating Megaproject Cost Overruns: Putting Changes Into Perspective}

- Mišić, S., \& Radujković, M. (2015). Critical Drivers of Megaprojects Success and Failure. Procedia Engineering, 122(Orsdce). Crossref

- Mok, K. Y., Shen, G. Q., \& Yang, J. (2015). Stakeholder management studies in mega construction projects: A review and future directions. International Journal of Project Management, 33(2). Crossref

- Pau, F., Langeland, A., \& Njå, B. O. (2016). Assessing cultural influences in megaproject practices. IEEE Engineering Management Review, 44(2). Crossref

- Pollack, J., Biesenthal, C., Sankaran, S., \& Clegg, S. (2018a). Classics in megaproject management: A structured analysis of three major works. International Journal of Project Management, 36(2). Crossref

- Pollack, J., Biesenthal, C., Sankaran, S., \& Clegg, S. (2018b). Classics in megaproject management: A structured analysis of three major works. International Journal of Project Management. Crossref

- Reuters. (2018). What is next for Mexico City airport after mega project axed? - Reuters. Retrieved April 7, 2019, from https://www.reuters.com/article/us-mexico-airport/what-isnext-for-mexico-city-airport-after-mega-project-axed-idUSKCN1N51BQ

- Room, G. (2018). The Hiding Hand: A Rejoinder to Flyvbjerg on Hirschman. World Development, 103. Crossref

- Siemiatycki, M. (2018a). The making and impacts of a classic text in megaproject management: The case of cost overrun research. International Journal of Project Management, 36(2). Crossref

- Siemiatycki, M. (2018b). The making and impacts of a classic text in megaproject management: The case of cost overrun research. International Journal of Project Management. Crossref

- Söderlund, J. I, Sankaran, S. I, Biesenthal, C., Söderlund, J., Sankaran, S., \& Otto, W. -. (2017). The Past and Present of Megaprojects. Project Management Journal, 48(6), 5-16. Retrieved from https://www.pmi.org/learning/library/past-present-megaprojects-10985 Crossref

- Statista. (2019). - Building construction industry: employed persons 2008-2016 | EU-28. Retrieved April 30, 2019, from https://www.statista.com/statistics/763219

- Transcity Rail. (2019). Rail News Hub - Network Rail News | Rail Technology Magazine. Retrieved April 7, 2019, from http://www.railtechnologymagazine.com/Rail-News

- Turner, J. R. (2018). The management of the project-based organisation: A personal reflection. International Journal of Project Management, 36. Crossref

- Van Marrewijk, A., Smits, K., Clegg, S. R., Pitsis, T. S., \& Veenswijk, M. (2008). Managing public-private megaprojects: Paradoxes, complexity, and project design. International Journal of Project Management, Crossref

- Van Marrewijk, A., Veenswijk, M., \& Clegg, S. (2014). Changing collaborative practices through cultural Crossref

- Van Marrewijk, A., Ybema, S., Smits, K., Clegg, S., \& Pitsis, T. (2016). Clash of the Titans: Temporal Organizing and Collaborative Dynamics in the Panama Canal Megaproject. Organisation Studies, 37(12). Crossref

- World Bank (2019) World Bank Open Data I Data. Retrieved March 18, 2019, from https://data.worldbank.org/

- Zidane, Y. J.-T., Johansen, A., \& Ekambaram, A. (2013). Megaprojects-Challenges and Lessons Learned. Procedia - Social and Behavioral Sciences. Crossref 